\title{
A Comparison of Trends in Extreme Rainfall Using 20-Year Data in Three Major Cities in Oman
}

\author{
L.N. Gunawardhana* and G.A. Al-Rawas \\ Department of Civil and Architectural Engineering, College of Engineering, Sultan Qaboos University, Oman.
}

Received 25 November 2015; Accepted 9 March 2016

\begin{abstract}
Many regions in the world have recently experienced more frequent and intensive disasters such as flash floods and persistent droughts. The Sultanate of Oman is no exception to this. We analyzed twodecade long daily precipitation records in three major cities, namely, Sohar, Muscat and Salalah, mainly focusing on extremes. A set of climate indices defined in the RClimDex software package was used. Moreover, annual maximum 1-day precipitations in three study areas were analyzed using the Generalized Extreme Value (GEV) distribution function. Results showed significant changes in the precipitation regime in recent years. The annual total precipitation in Sohar and Salalah decreased, while that in Muscat shows statistically week increasing trend. However, all indices analyzed indicate enhanced extreme precipitation toward 2010 in Muscat and Salalah. As a result, the contribution from extreme events to the annual total rainfall steadily increases in both study areas. A clear conclusion could not be made based on selected indices for Sohar due to consistent drier years occurred from 1999 to 2005 . Frequency analysis indicates that the annual the maximum 1-day rainfall estimated in Sohar and Muscat for 5 and 10 year return periods are approximately same $(70 \mathrm{~mm} /$ day and $108 \mathrm{~mm} /$ day, respectively) but about two-fold greater than that in Salalah $(29 \mathrm{~mm} /$ day and $60 \mathrm{~mm} /$ day, respectively).
\end{abstract}

Keywords: GEV distribution, RClimDex, Rx-1day, Sohar, Muscat, Salalah.

\section{مقارنة بين أنماط الأمطار الغزيرة المتطرفة عن طريق استخدام بيانات ·r سنة ِِّ ثلاث مدن رئيسة (2) عمان لوميندا نيروشانا جوناواردانا" ، وغازي بن على الرواس}

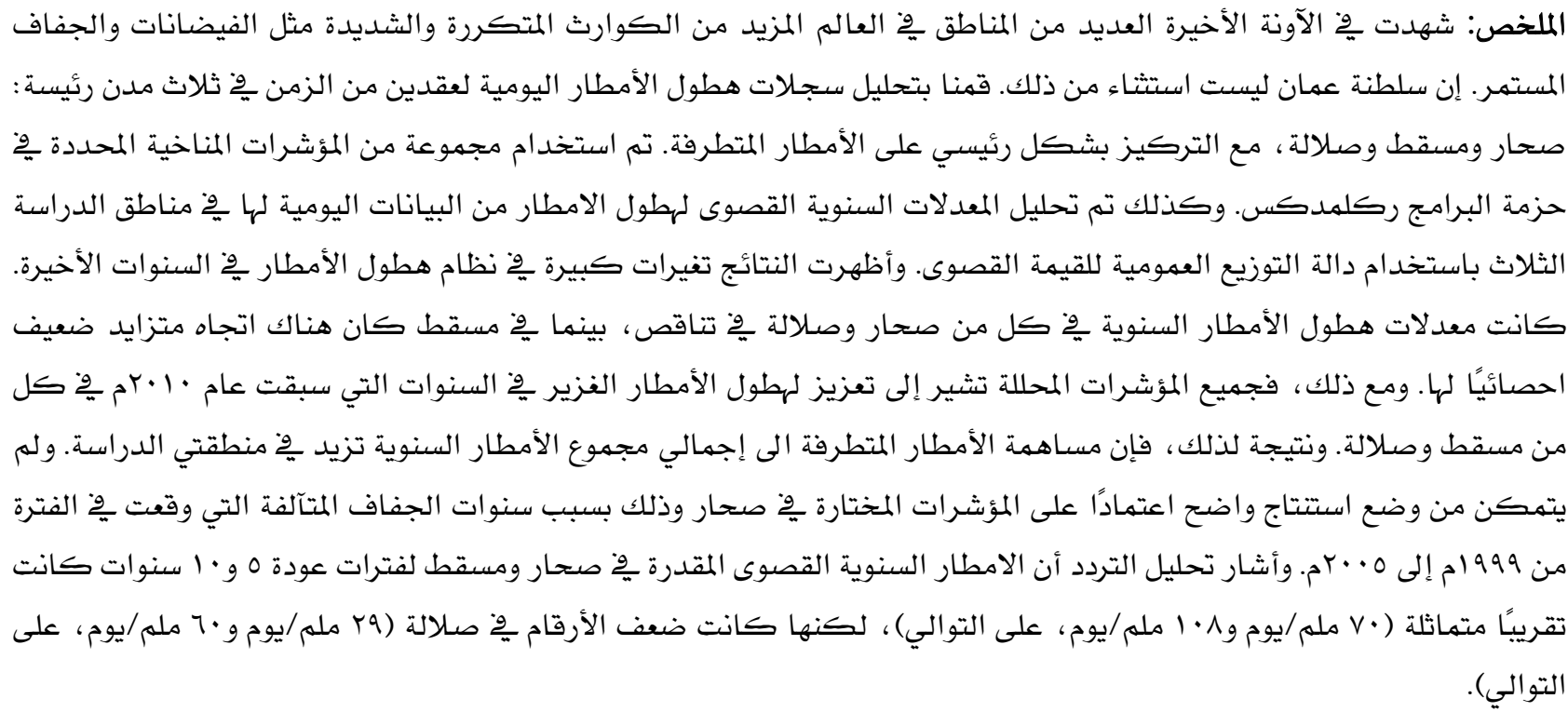

الكلمات المفتاحية: التوزيع الاحتمالي، حزمة البرنامج ركلمدكس، الامطار السنوية القصوى لمدة يوم واحد، صحار، مسقط، صلالة

*Corresponding author's e-mail: luminda@squ.edu.om 


\section{Introduction}

In recent decades, weather has gotten more extreme in many parts of the world. These changes have been detected in the Arabian Peninsula (AlSarmi and Washigton 2013), Asia (Liu et al. 2015), America (Coopersmith et al. 2014), and Europe (Haren et al. 2013). In a regional scale analysis, Groisman et al. (2005) reported that in the mid-latitudes there has been a notable increase in the frequency of very heavy precipitation (upper $0.3 \%$ of daily precipitation) during the past 50-100 years. Alexander et al. (2006) reported a significant decrease in the annual occurrence of cold nights and a significant increase in the annual occurrence of warm nights over two-thirds of the global land area. These extreme weather events often cause extensive damage to economies, the environment, and human life (Tezuka et al. 2014). For example, exposure to extreme heat can cause heat stroke, which may lead to death or permanent disability. Changes in a precipitation regime may result in flash floods and long-term droughts. Moreover, some plants and animals are highly dependent on specific climate conditions. Any changes in the climate of an area can affect them and the entire ecosystem (Tank et al. 2009).

Consequences of extreme weather events affect regions in different ways, and are projected to worsen conditions in water-scarce countries like Oman. Gunasekara et al. (2013) analyzed the combined impact of population change and climate change, and identified the Middle East as one of four regions that will be exposed to extremely negative impacts that could lower fresh water availability by $50 \%$ by 2100 compared to the situation in 2000. In Oman, changes in precipitation and temperature have already begun to be detected. For example, the super cyclone Gonu in 2007 caused extensive damage in coastal cities, with rainfall recorded at $256 \mathrm{~mm} /$ day at Seeb Airport in Muscat Governorate. The cyclone caused about USD $\$ 4.4$ billion in damages at the time and 69 deaths.

Numerous studies based on global circulation model (GCM) and regional climate model (RCM) projections indicate that anthropogenic climate change could cause an increase in the frequency and intensity of extreme weather events (Beniston et al. 2007; Fowler et al. 2005). Under changing climate conditions (past and future), exclusive use of climatic norms derived from historical data may no longer be appropriate and could render infrastructure vulnerable by leading to design with insufficient capacity or by prompting the adoption of policy measures that become difficult to practice over time. Therefore, understanding the occurrence of past extremes is of great importance to avoid or at least reduce the damage due to catastrophic floods and prolonged periods of drought. The objective of this research is therefore to evaluate the trends of extreme precipitation in three of Oman's major cities - Muscat, Salalah, and Sohar - over recent decades.

\section{Study Area}

Oman is located in the southeastern corner of the Arabian Peninsula. It covers an area of $309,500 \mathrm{~km}^{2}$ and encompasses a diverse range of topography, including mountain ranges, arid deserts, and fertile plains. The climate varies mainly from semi-arid to hyper-arid. On average, annual rainfall is less than $100 \mathrm{~mm}$ compared to a global annual mean of 1,123 $\mathrm{mm}$.

The city of Sohar is located in Al Batinah North Governorate in northern Oman (Fig. 1). The annual total precipitation average between 1991-2010 was approximately 106 mm (Fig. 2), which suggests a strong negative trend in rainfall in the $21^{\text {st }}$ century $(67 \mathrm{~mm} /$ decade, $P=$ $0.05)$. A $P$-value of $<0.05$ leads a researcher to reject the null hypothesis and conclude that there is a significant linear trend. Cold frontal troughs originating in the North Atlantic Ocean or Mediterranean Sea bring nearly $75 \%$ of

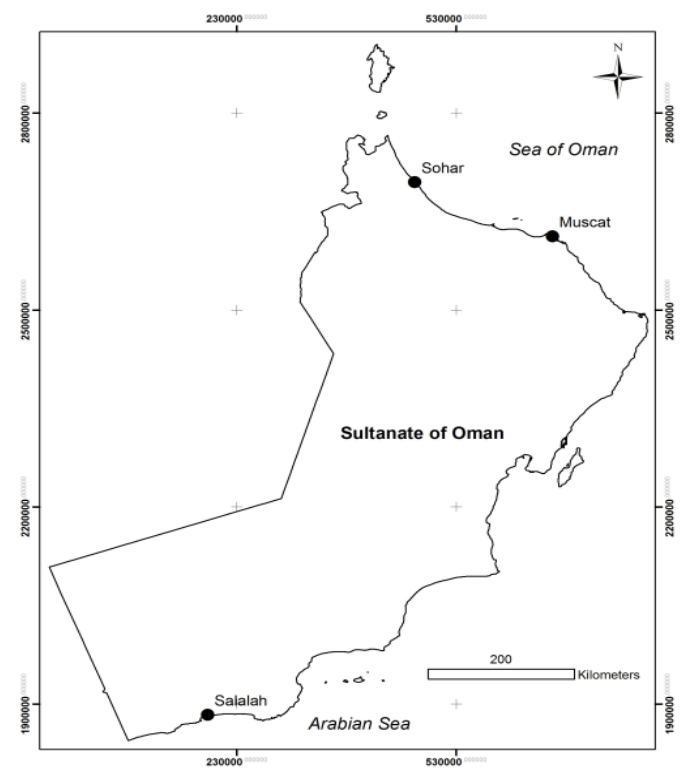

Figure 1. Three study areas. 
Sohar's total rainfall from November to April (Fig. 3). The number of wet days, which are defined as days with precipitation $>1 \mathrm{~mm}$, occur in Sohar about 11.7 days/year, which is higher than the number of wet days that occur in Muscat (7 days/year), but is significantly lower than the number of wet days in Salalah $(25$ days/year). Sohar's monthly mean minimum temperature fluctuates between $14-29^{\circ} \mathrm{C}$, while

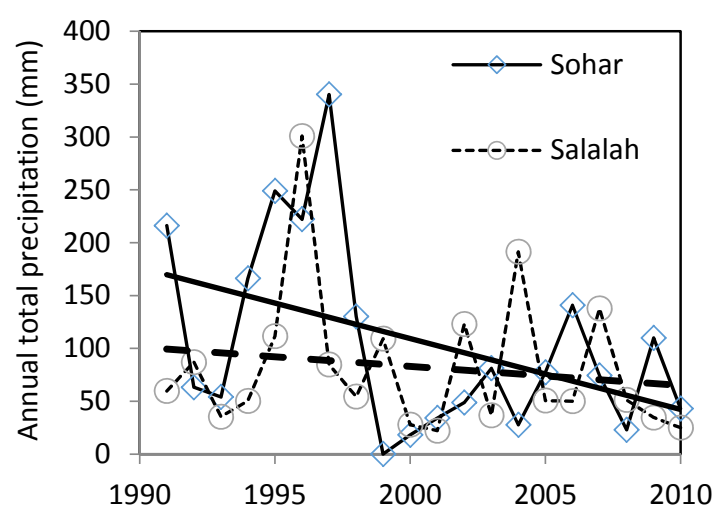

the monthly mean maximum temperature ranges between $24-36^{\circ} \mathrm{C}$.

Muscat, the capital city, accommodated approximately $29.5 \%$ of the total population in Oman in 2010. The annual total precipitation average from 1991-2010 was approximately 87 $\mathrm{mm}$, showing a statistically weak trend, with precipitation increasing at an average rate of 18

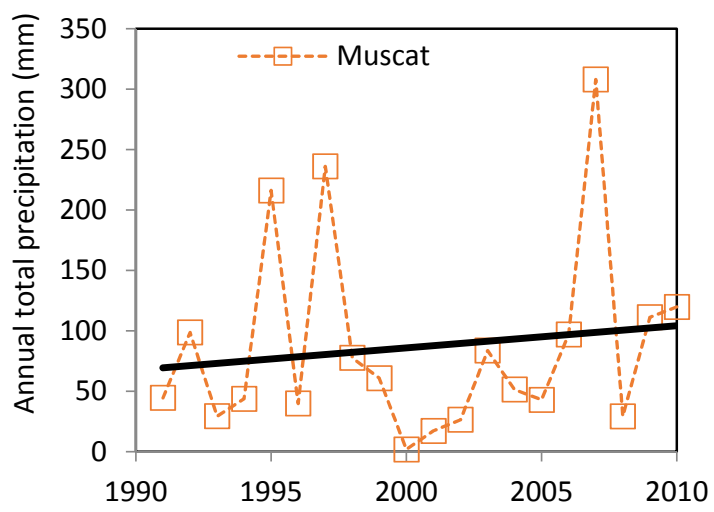

Figure 2. Variations of annual total precipitation in three study areas.

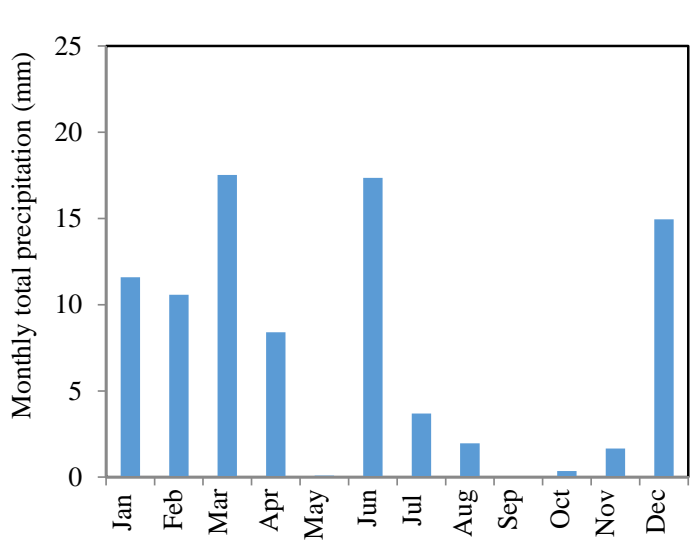

Muscat
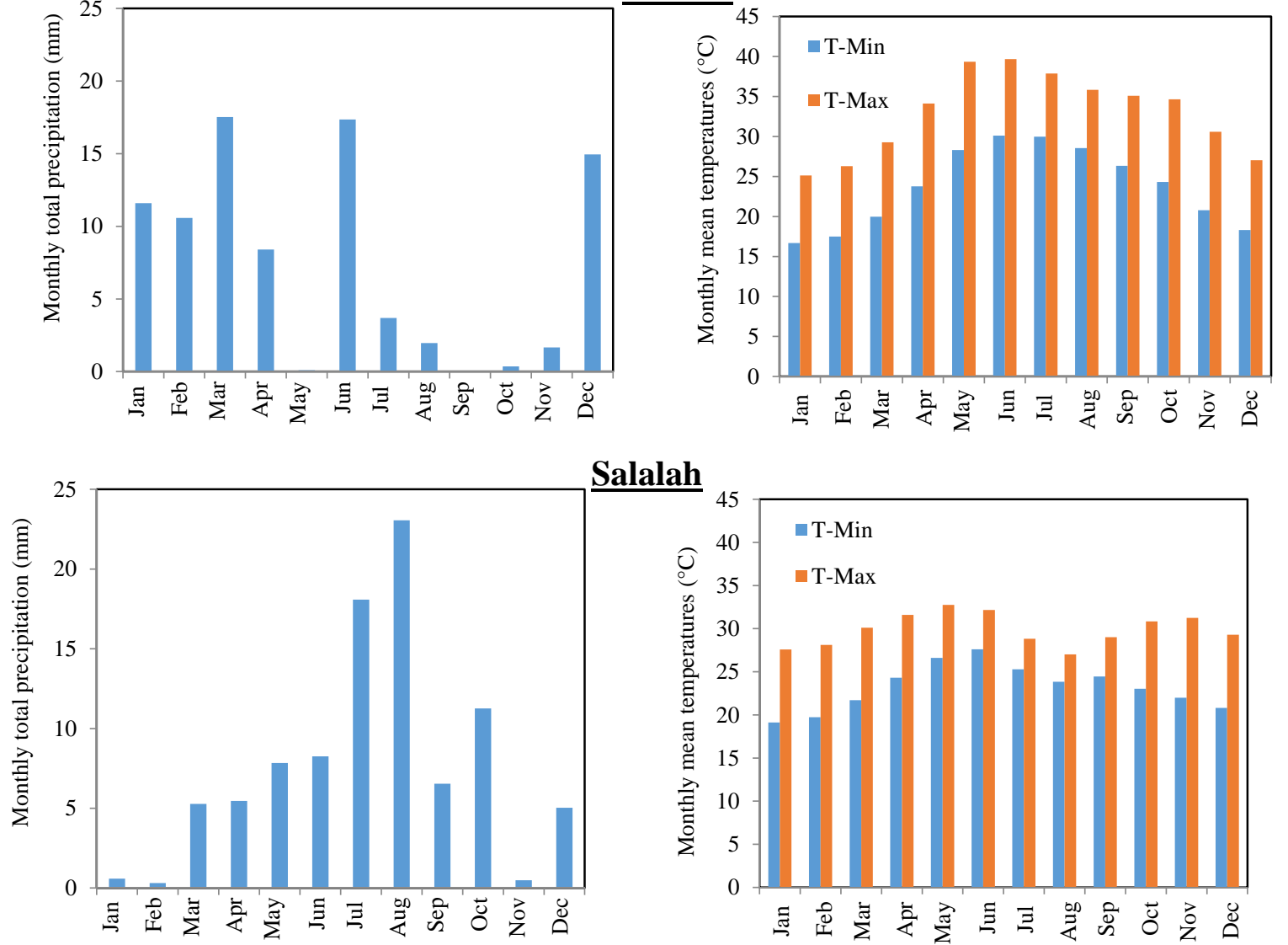

Salalah

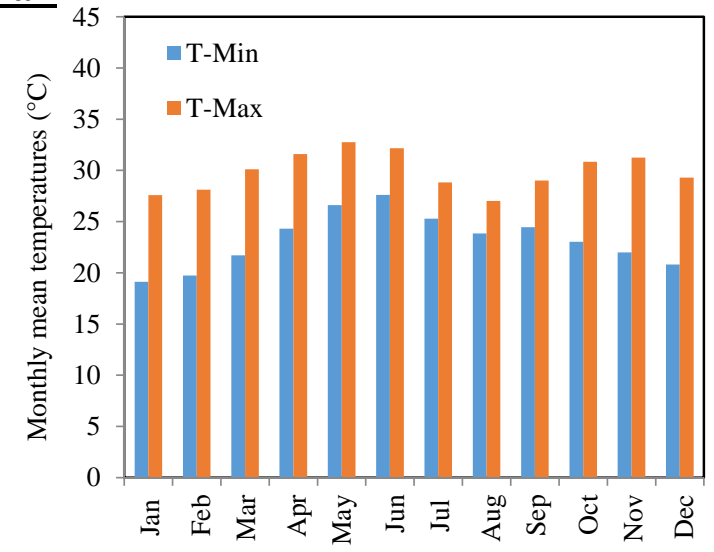

Figure 3. Monthly precipitation and temperature variations in two study areas (Muscat and Salalah). 
$\mathrm{mm} /$ decade $(P=0.57)$ (Fig. 2$)$. About $73 \%$ of the annual total precipitation occurs from November to April when the cold frontal troughs are active (Fig. 3). In addition, tropical cyclones originating in the Arabian Sea bring intense rainfall during the pre-monsoon (MayJune) and post-monsoon (October-November) seasons. Even though these cyclones are uncommon and their contribution is not apparent in long-term averages, they occasionally bring heavy rains to the coastal areas, causing substantial damages. The monthly mean maximum temperature in Muscat fluctuates between $25-40^{\circ} \mathrm{C}$, and the monthly mean minimum temperature ranges between $17-29^{\circ} \mathrm{C}$ (Fig. 3).

The city of Salalah is located in the Dhofar Governorate in southern Oman (Fig. 1). Summer months are cooler than in the northern regions of the country; thus, Salalah attracts tourists from the other parts of Oman and neighboring countries. From late June to September, the region experiences monsoon precipitation, known locally as the Khareef, which brings approximately $61 \%$ of the total precipitation for the year (Fig. 3). High humidity and drizzle are common through the Khareef season. As a result, Salalah experiences about 25 wet days per year. The annual total precipitation average from 1991-2010 is $82 \mathrm{~mm}$, which shows a statistically weak negative trend of $-18 \mathrm{~mm} /$ decade $(P=$ 0.51 ) (Fig. 2). The monthly mean maximum temperature fluctuates between $27-33^{\circ} \mathrm{C}$, and the monthly mean minimum temperature ranges between $19-28^{\circ} \mathrm{C}$ (Fig. 3).

\section{Methodology}

Oman's daily precipitation records between 1991-2010 were used. In the current study, RClimDex software developed by the Expert Team on Climate Change Detection, Monitoring and Indices (ETCCDMI) was used to calculate nine indices that analyze different aspects of precipitation under changing climate conditions (Alexander et al. 2006). The quality control procedure in RClimDex was applied to identify errors in data processing, and a temporal homogeneity test was conducted using the RHtest software package. Climatic time series often exhibit abrupt changes and/or gradual shifts due to station relocation or changes in instruments or observing practices. However, no artificial step changes were detected in the time series of temperature or precipitation. Even though all nine indices were calculated, discussion is limited to the indices with hydrologically significant trends only. Definitions of the selected indices are presented below.

SDII: simple precipitation intensity index, where $R R_{W}$ is the daily precipitation amount on a wet day and $W$ represents the number of wet days (Eqn. 1).

$$
S D I I=\frac{\sum_{W=1}^{W} R R_{W}}{W}
$$

R10mm: annual count of days when daily precipitation is $\geq 10 \mathrm{~mm}$.

$R x$-1 day: annual maximum one-day precipitation.

R95pTOT: annual total precipitation when $R R w>95 p$. Here, $95 p$ is the $95^{\text {th }}$ percentile of precipitation on wet days in the base period (1991-2000).

$R 95 p T O T=\sum_{W=1}^{W} R R_{W}$ where $R R_{W}>95 p$

PRCPTOT: Annual total precipitation on wet days

PRCPTOT $=\sum_{W=1}^{W} R R_{W}$

This analysis was further extended to investigate the spatial variation of extreme rainfall for different return periods. The yearly maxima of the daily precipitation were analysed using the GEV distribution function (Demaria et al. 2013; Stahli et al. 2011). The cumulative probability distribution function for the GEV is given as in Eqn. 4.

$F_{(x ; \mu, \sigma, \xi)}=\exp \left[-\left(1+\xi \frac{x-\mu}{\sigma}\right)^{-1 / \xi}\right]$

for $\{1+[\xi(x-\mu) / \sigma]>0\}$. For the location $(\mu)$, scale $(\sigma)$ and shape $(\xi)$, parameters of this distribution were estimated by the maximum likelihood estimation (MLE) method (Jenkinson 1955). The goodness-of-fit of the fitted distribution was tested using the Kolmogorov-Smirnov (K-S) test, which examines the null hypothesis that sample data follow the specified distribution. The characteristics of the precipitation distributions were assessed in terms of the return values and return periods of their annual extremes. Given an annual exceedance 
probability of $P(X \leq x)$, the return period is calculated by the reciprocal of $P(X \leq x)$.

Return period $(T)=\frac{1}{P(X \leq x)}=\frac{1}{1-P(X>x)}$

A T-year return value is defined as the threshold that is exceeded by an annual extreme in any given year with the probability $P=1 / T$ (Kharin et al. 2007).

\section{Results and Discussion}

The trends of selected indices are not consistent in showing whether precipitation will increase or decrease over the three study areas (Table 1). Of the three precipitation time series examined, Muscat and Salalah exhibited similar characteristics in trends analysis, while findings for Sohar revealed results that are distinct from the other two cities. This can be attributed to the consecutive number of dry years which occurred for seven years, beginning in 1999, in Sohar (Fig. 2). For example, the total annual precipitation in Sohar from 1991-1998 was 180 $\mathrm{mm} /$ year but was reduced to $56 \mathrm{~mm}$ /year from 1999-2010. Therefore, calculations made relative to reasonably higher annual total precipitation rates in the past resulted in notably smaller estimations in recent years, suggesting a negative trend for precipitation indices overall (Figs. 4 and 5).

Even though Muscat and Salalah depict similar trends for most selected indices, their magnitudes were found to be significantly different. For example, the average annual Rx1 day rate over 20 years in Muscat and Sohar was approximately $42 \mathrm{~mm} /$ day and 48 $\mathrm{mm} /$ day, respectively, while in Salalah it was only $22 \mathrm{~mm} /$ day (Fig. 4). Similarly, the average wet day intensity (SDII) estimated in Muscat and Sohar was approximately $14 \mathrm{~mm}$ /day and $12 \mathrm{~mm} /$ day, respectively. In Salalah, this figure decreased by more than three-fold (3.6 $\mathrm{mm} /$ day). This difference has been mainly attributed to a comparatively higher number of rainy days and the drizzly, low-intensity rainfall events common during the Khareef season in Salalah. The $95^{\text {th }}$ percentile of the precipitation rates on rainy days during the study period were calculated. Rainfall events that result in precipitation rates above the $95^{\text {th }}$ percentile are generally accepted as extreme (Alexander et al. 2006). This threshold in Salalah is approximately $13 \mathrm{~mm}$, while in Muscat it is approximately $43 \mathrm{~mm}$. Therefore, the 10 $\mathrm{mm} /$ day threshold determined when calculating the R10mm index (Fig. 4) can be considered a mild event for Muscat but an extreme event for Salalah.

Table 1. A summary of calculated indices.

\begin{tabular}{|c|c|c|c|}
\hline \multirow{2}{*}{ Index } & \multicolumn{3}{|c|}{ Linear regression fitted using the least squares approach } \\
\hline & Sohar & Muscat & Salalah \\
\hline Rx-1day & $\begin{array}{c}\text { Negative } \\
\left(\mathrm{R}^{2}=0.05, \mathrm{p} \text {-value }=0.001\right)\end{array}$ & $\begin{array}{c}\text { Positive } \\
\left(\mathrm{R}^{2}=0.31, \mathrm{p} \text {-value }=0.016\right)\end{array}$ & $\begin{array}{c}\text { Positive } \\
\left(\mathrm{R}^{2}=0.39, \mathrm{p} \text {-value }=0.090\right)\end{array}$ \\
\hline $\mathrm{R} 10 \mathrm{~mm}$ & $\begin{array}{c}\text { Negative } \\
\left(\mathrm{R}^{2}=0.10, \mathrm{p} \text {-value }=0.197\right)\end{array}$ & $\begin{array}{c}\text { Negative } \\
\left(\mathrm{R}^{2}=0.14, \mathrm{p} \text {-value }=0.123\right)\end{array}$ & $\begin{array}{c}\text { Positive } \\
\left(\mathrm{R}^{2}=0.005, \mathrm{p} \text {-value }=0.197\right)\end{array}$ \\
\hline SDII & $\begin{array}{c}\text { Negative } \\
\left(\mathrm{R}^{2}=0.39, \mathrm{p} \text {-value }=0.001\right)\end{array}$ & $\begin{array}{c}\text { Positive } \\
\left(\mathrm{R}^{2}=0.39, \mathrm{p} \text {-value }=0.090\right)\end{array}$ & $\begin{array}{c}\text { Positive } \\
\left(\mathrm{R}^{2}=0.39, \mathrm{p} \text {-value }=0.073\right)\end{array}$ \\
\hline$\frac{\text { R95PTOT }}{\text { PRCPTOT }}$ & $\begin{array}{c}\text { Negative } \\
\left(\mathrm{R}^{2}=0.31, \mathrm{p} \text {-value }=0.010\right)\end{array}$ & $\begin{array}{c}\text { Positive } \\
\left(\mathrm{R}^{2}=0.005, \mathrm{p} \text {-value }=0.197\right)\end{array}$ & $\begin{array}{c}\text { Positive } \\
\left(\mathrm{R}^{2}=0.042, \mathrm{p} \text {-value }=0.250\right)\end{array}$ \\
\hline
\end{tabular}




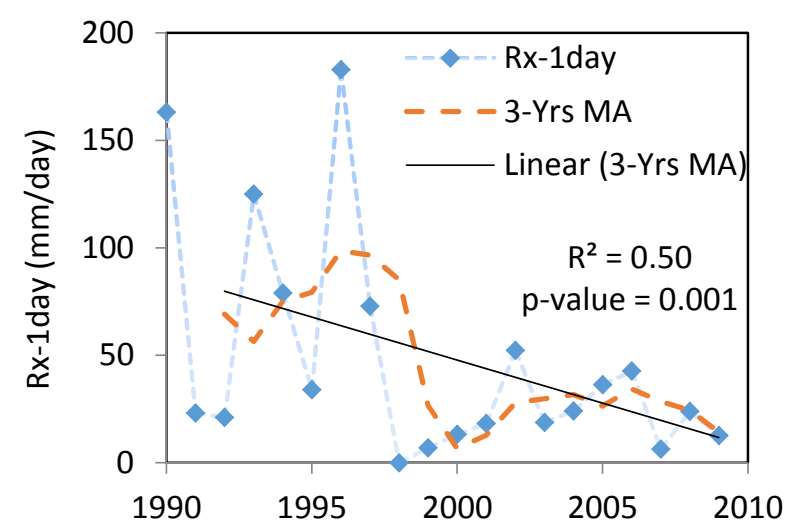

(a)

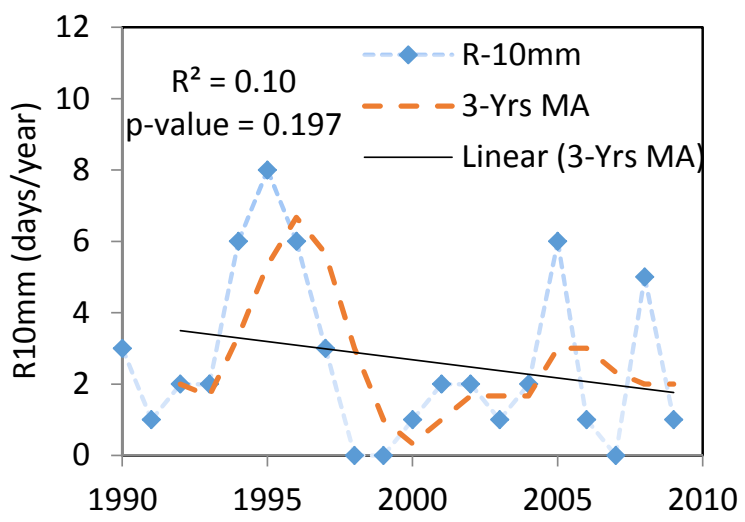

(b)
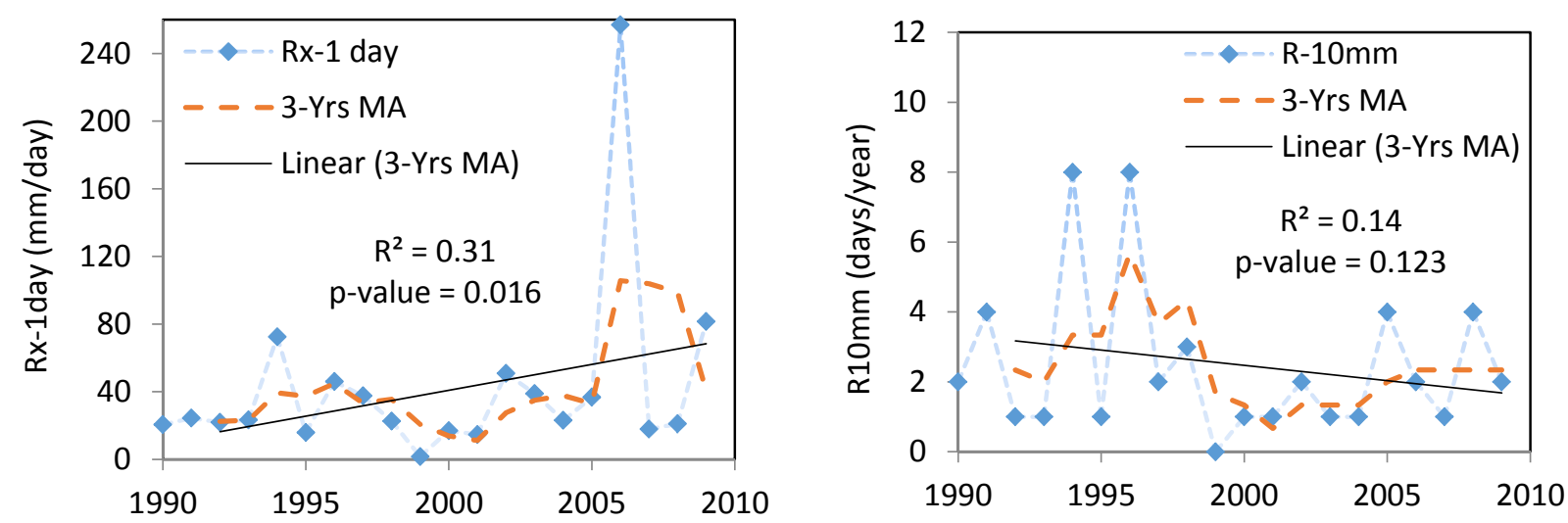

(c)
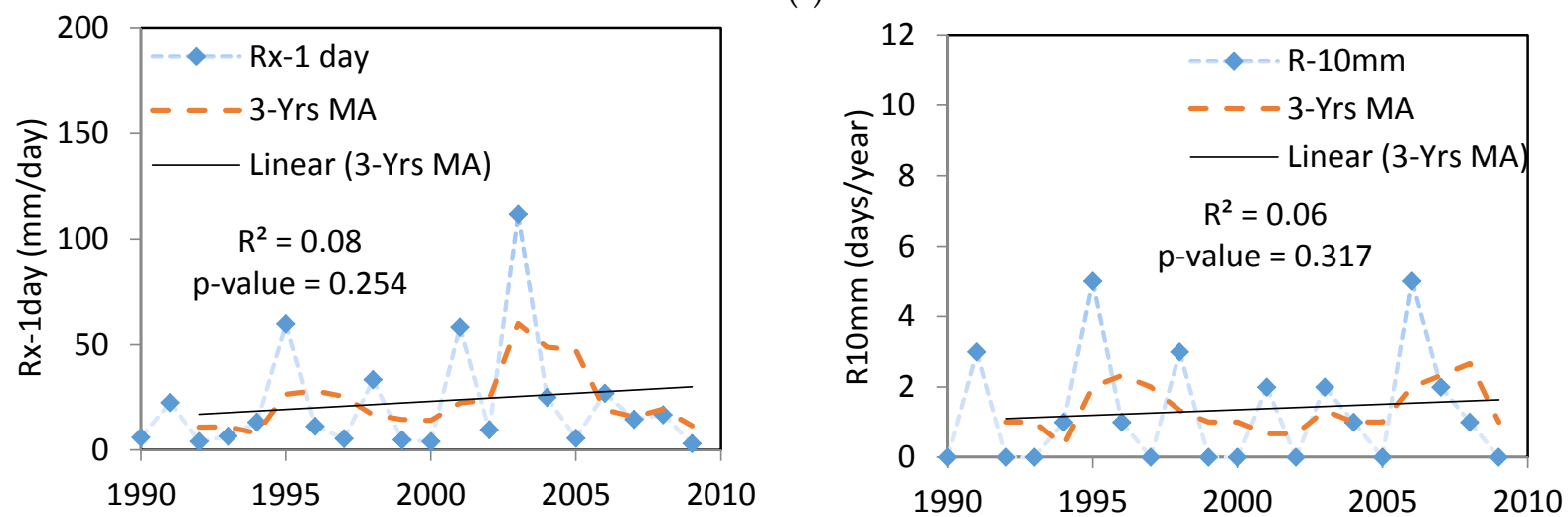

Figure 4. Trends in Rx-1day and R10mm indices: (a) Sohar, (b) Muscat, and (c) Muscat.

All indices examined in Muscat indicated increases in precipitation intensity over the past 20 years. The annual Rx-1day (Fig. 4) and average SDII (Fig. 5) suggested positive trends with reasonably high statistical significance $(P$ value $=0.016$ and 0.005 , respectively). Moreover, the number of days with mild rainfall intensity as calculated by the $\mathrm{R} 10 \mathrm{~mm}$ index depicts a statistically weak negative trend.
To understand the effect of extreme precipitation on the total annual precipitation, the ratio between $\mathrm{R} 95 \mathrm{pTOT}$ and the total annual precipitation (PRCPTOT) was calculated. As the R95pTOT index gives the total annual precipitation generated by extreme events, the R95pTOT/PRCPTOT ratio indicates the contribution from the extreme rainfall to the total annual precipitation. This ratio in Muscat (Fig. 5) increased between 1991 - 2010, sugges- 


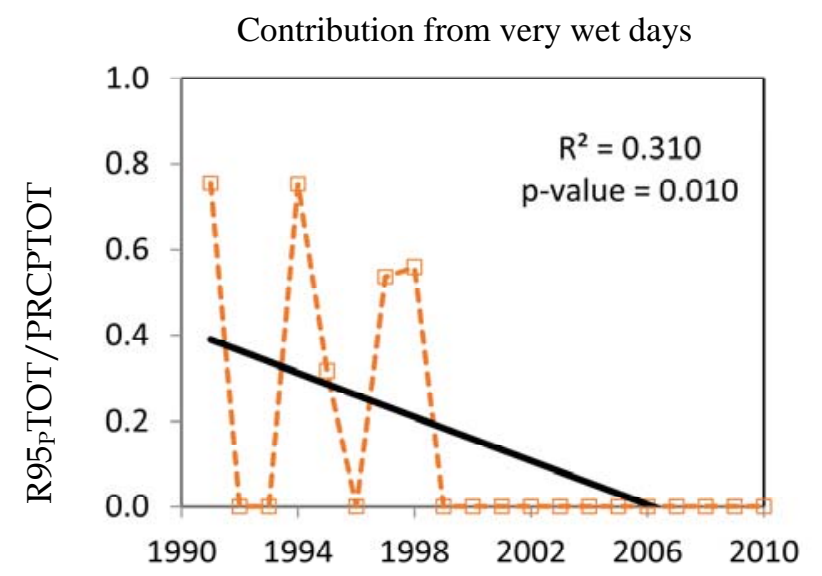

(a)

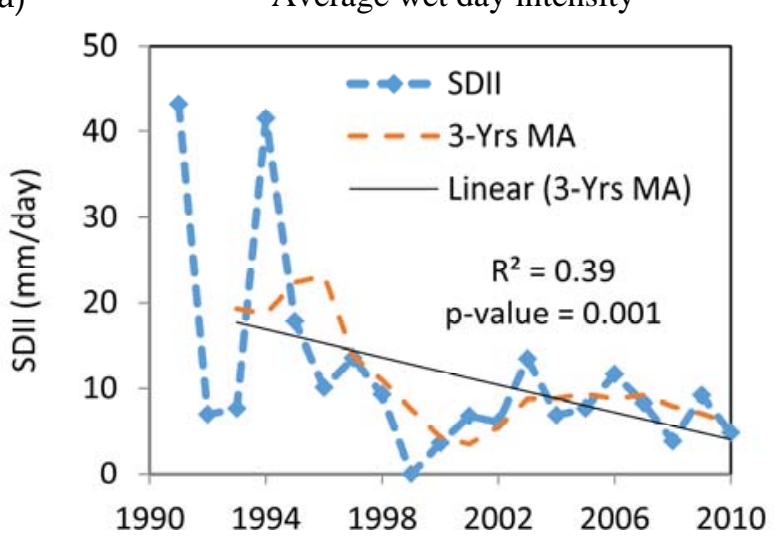

Contribution from very wet days

(b)
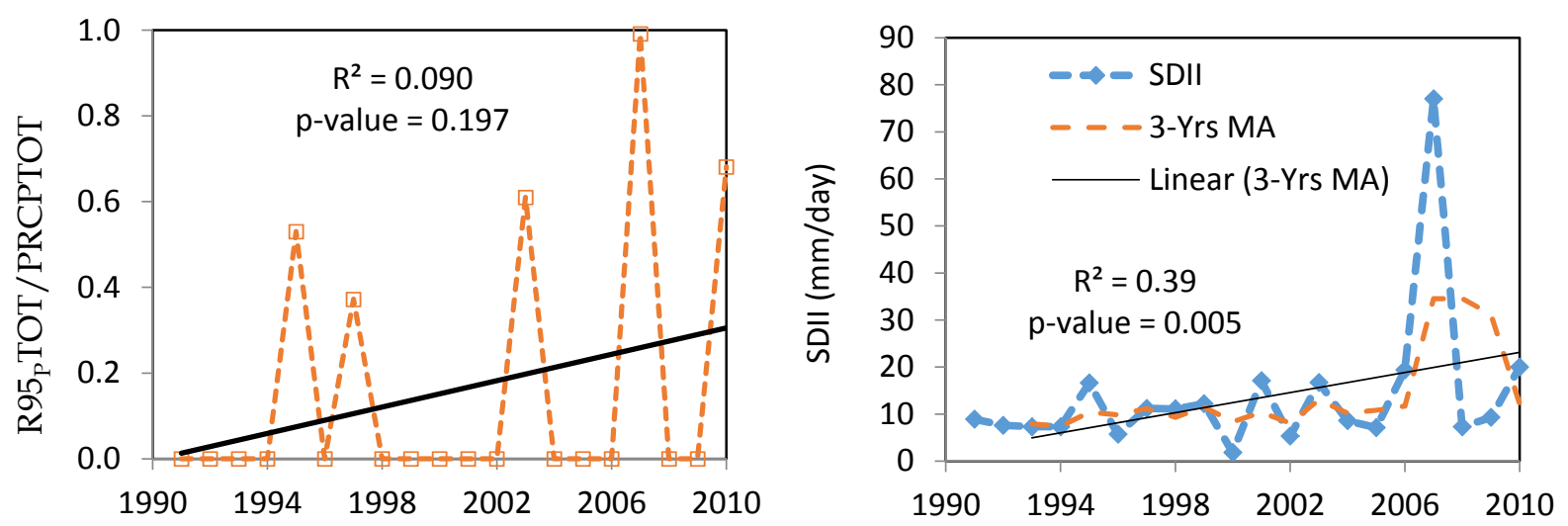

(c)

Contribution from very wet days
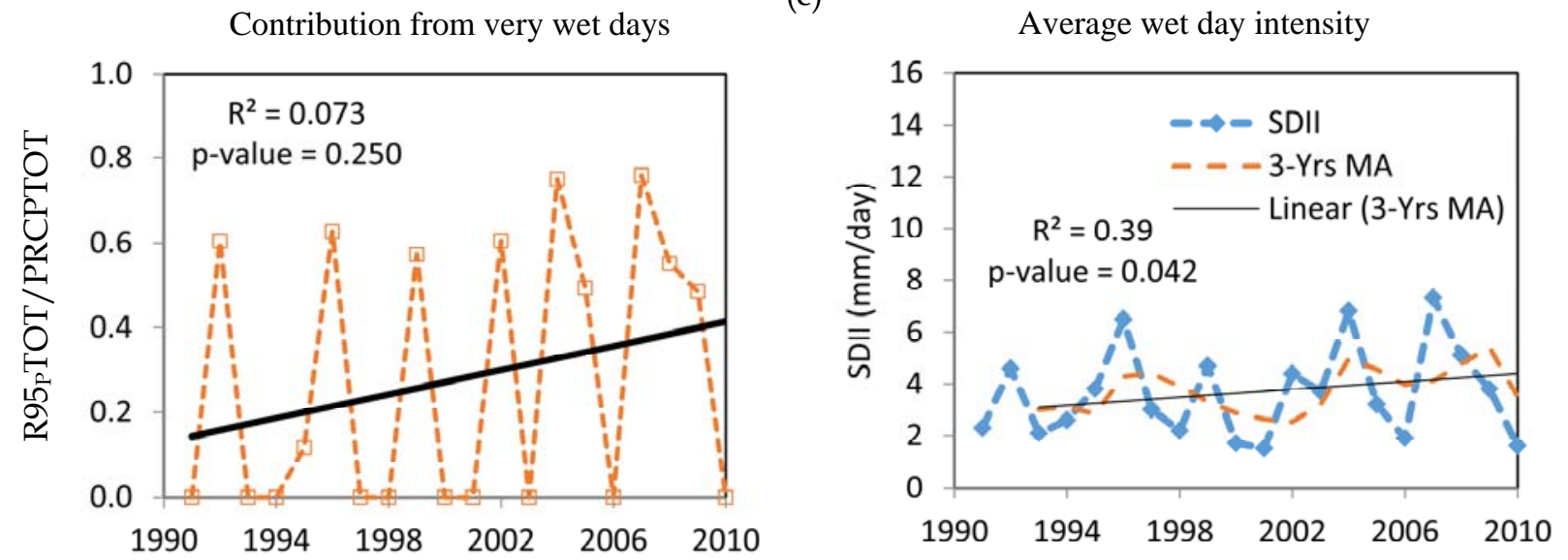

Figure 5. Trends in contribution from very wet days and average wet day intensity: (a) Sohar, (b) Muscat, and (c) Muscat.

ting enhanced extreme precipitation events over the study period.

All indices calculated for Salalah indicate evidence for increased precipitation intensity, even though the trend estimations were not found to be statistically significant (Figs. 4 and 5). However, despite the decreases in total annual precipitation estimates for Salalah (Fig. 2), the R95pTOT / PRCPTOT ratio suggests that the contribution from extreme rainfall to the total annual precipitation has steadily increased.

Intensity-duration-frequency (IDF) curves are used in designing hydraulic structures such as dams and open channels. The extreme value theory that produces the relationship between the intensity and return periods for selected durations requires the time series to be 
stationary. Extreme events observed within the study period of the current research (eg. Cyclone Gonu in 2007), however, lie outside the envelope of constant variability assumed under stationary climate conditions. In such situations, the World Meteorological Organization (WMO) recommends conducting an analysis, assuming the non-stationarity within the time periods is sufficiently small, or using more advanced methods in which the parameters in the statistical models vary over time to describe the temporal evolution of the extremes (Tank et al. 2009). Inclusion of a trend in one or more parameters of the GEV distribution implies a return level for a particular return period change over time; therefore, no return-level plot can be produced. The researchers in the current study used the second method, introducing a linear trend to one of the parameters in the GEV distribution. The most suitable parameter to consider the time variant was decided by the negative log-likelihood value produced by the MLE method. Table 2 shows the constrained parameters in their study areas. Furthermore, Fig. 6 shows the estimated Rx-1day for the 10year return period with observed $\mathrm{Rx}-1$ day values plotted over the study period. In all three study areas, no major change in return levels was observed between 1991-2010. Inspection of the standard error (Table 2) shows that the value for the time variant parameter is much lower than its standard error. It is therefore concluded that the consideration of a time variant trend for more than one parameter could further increase the uncertainty of the results. These results also suggest that the assumption of stationarity is reasonably valid to generate IDF curves in the three study areas. In order to understand the differences in frequency and intensity of extreme precipitation in the three study areas, GEV parameters were estimated under a stationary assumption (Table 3). The standard error in parentheses reveals that the shape parameter is always larger than the standard deviation, which rejects a twoparameter distribution, also called a Gumbel distribution, for all the time series. The K-S test results indicated good agreement between observations and modelled probabilities. A reasonably higher shape parameter in Salalah may represent an increase in the annual Rx1day precipitation compared to the other two study areas. In contrast, the location and smaller scale parameters in Salalah compared to those in Muscat and Sohar can be attributed to the smaller intensity rainfall events.

The plot of results from the frequency analysis allows an estimate of the expected return levels (annual Rx1-day rainfall) for different return periods (Fig. 7). Moreover, Fig. 8 was produced to compare the annual Rx1-day rainfall estimated for 5-, 10-, and 20-year return

Table 2. Estimated parameters of the GEV distribution under non-stationary condition.

\begin{tabular}{|c|c|c|c|}
\hline \multirow{2}{*}{$\begin{array}{c}\text { Study } \\
\text { area }\end{array}$} & \multicolumn{3}{|c|}{ Parameters of the GEV distribution } \\
\hline & Location $(\mu)$ & Scale $(\sigma)$ & Shape $(\xi)$ \\
\hline Sohar & $\begin{array}{c}22.28+[-0.138 \times(\text { year- } \\
1990)]\{13.24,0.922\}\end{array}$ & $20.48\{5.24\}$ & $0.5099\{0.2580\}$ \\
\hline Muscat & $\begin{array}{c}21.02+[0.124 \times(\text { year- } \\
1990)]\{8.66,0.774\}\end{array}$ & $16.32\{3.43\}$ & $0.3431\{0.1575\}$ \\
\hline Salalah & $\begin{array}{c}7.44+[-0.066 \times(\text { year }-1990)] \\
\{1.57,0.040\}\end{array}$ & $5.16\{2.17\}$ & $1.298\{0.4534\}$ \\
\hline
\end{tabular}

Table 3. Estimated parameters of the GEV distribution under stationary climate conditions.

\begin{tabular}{lccccc}
\hline \multirow{2}{*}{$\begin{array}{c}\text { Study } \\
\text { area }\end{array}$} & \multicolumn{2}{c}{ Parameters of the GEV distribution } & $\begin{array}{c}\text { K-S test } \\
\text { significant } \\
\text { at 5\% } \\
\text { level }\end{array}$ & $\begin{array}{c}\text { Reject } \\
\text { Gumbel } \\
\text { Hypothesis }\end{array}$ \\
\hline Sohar & $20.45\{5.22\}$ & $20.31(5.11)$ & $0.5290\{0.2341\}$ & Yes & Yes \\
Muscat & $22.23\{3.99\}$ & $16.30(3.43)$ & $0.3449\{0.1572\}$ & Yes & Yes \\
Salalah & $7.43\{1.61\}$ & $6.02(2.14)$ & $1.0397\{0.3417\}$ & Yes & Yes \\
\hline
\end{tabular}

Standard errors are shown in parentheses. 


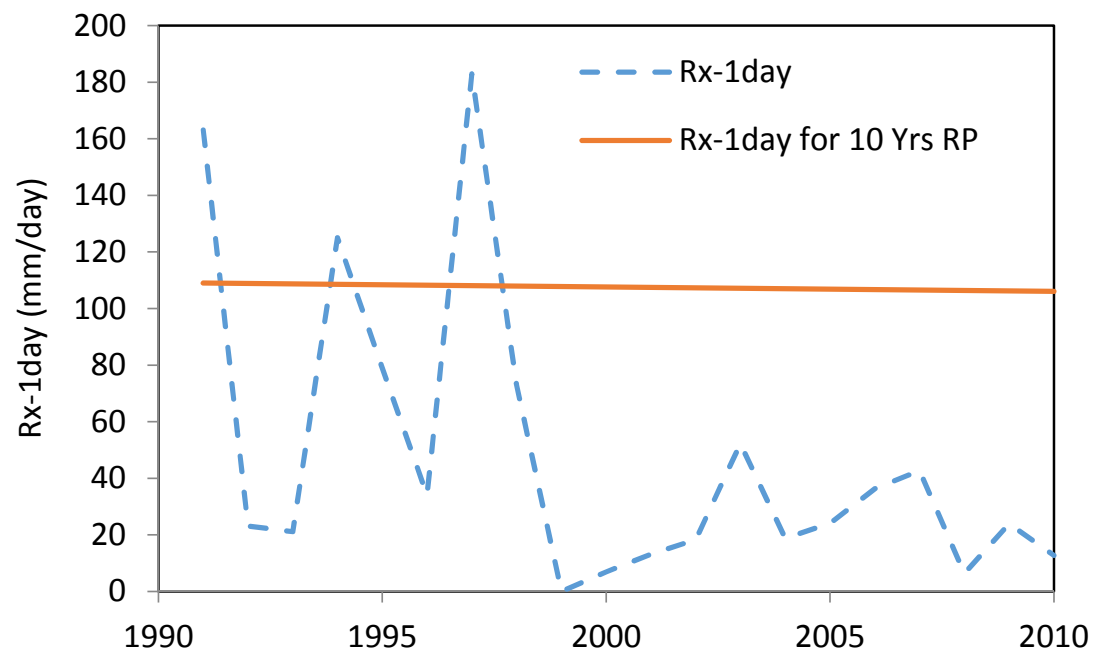

(a)

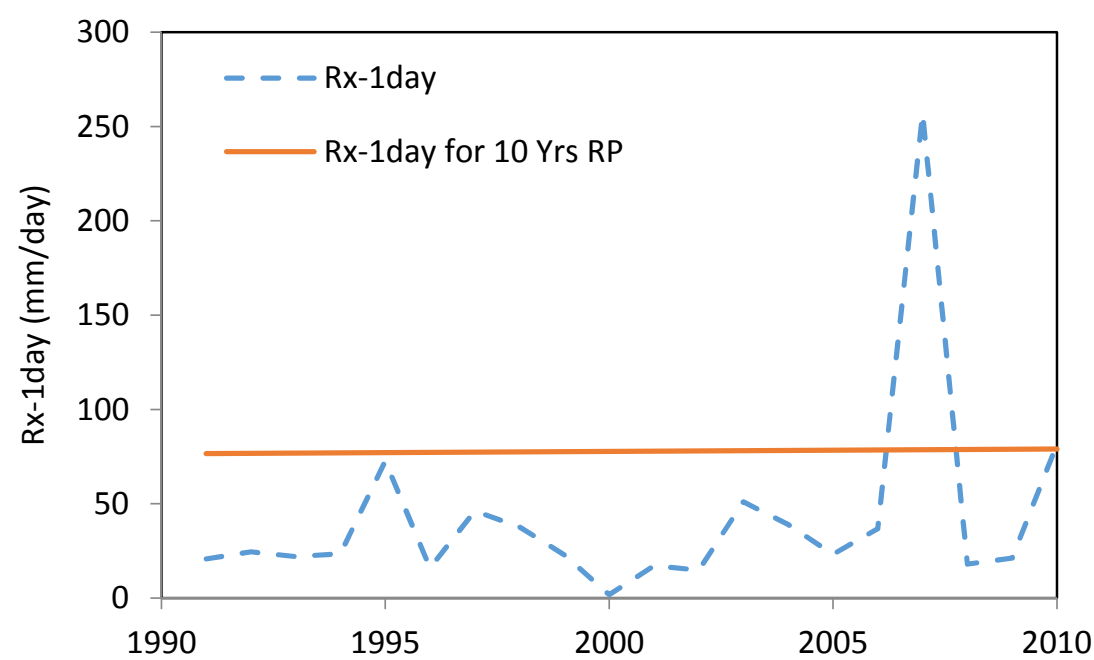

(b)

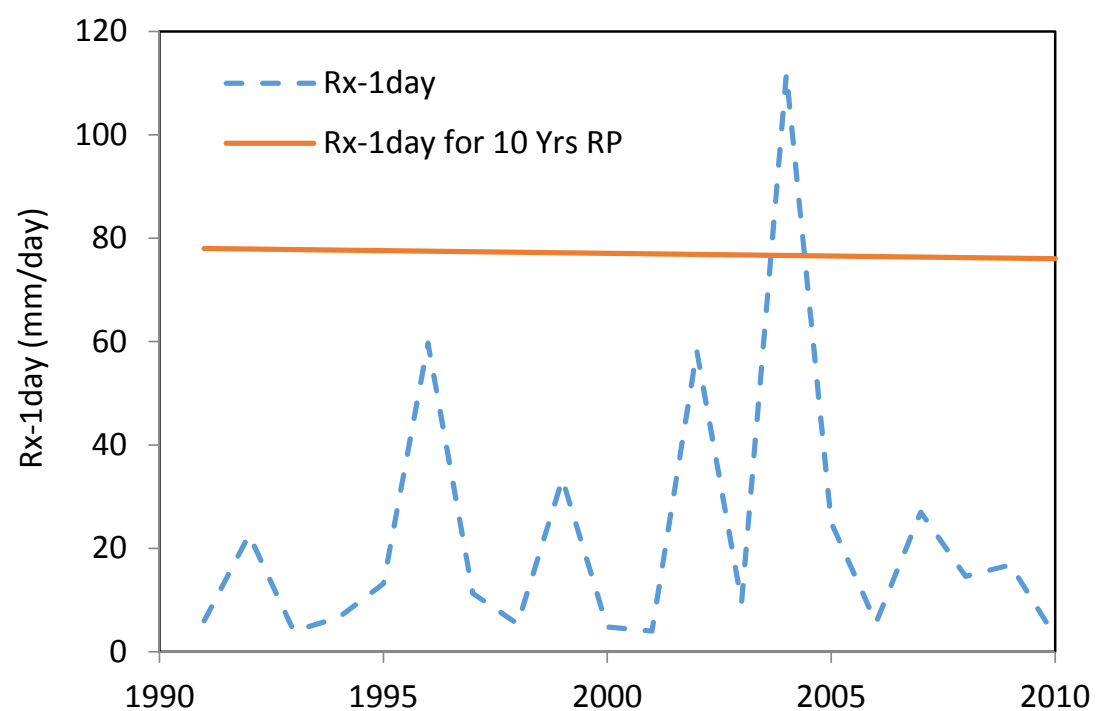

(c)

Figure 6. The 10-years return level estimated under non-stationary condition: (a) Sohar, (b) Muscat, and (c) Salalah. 


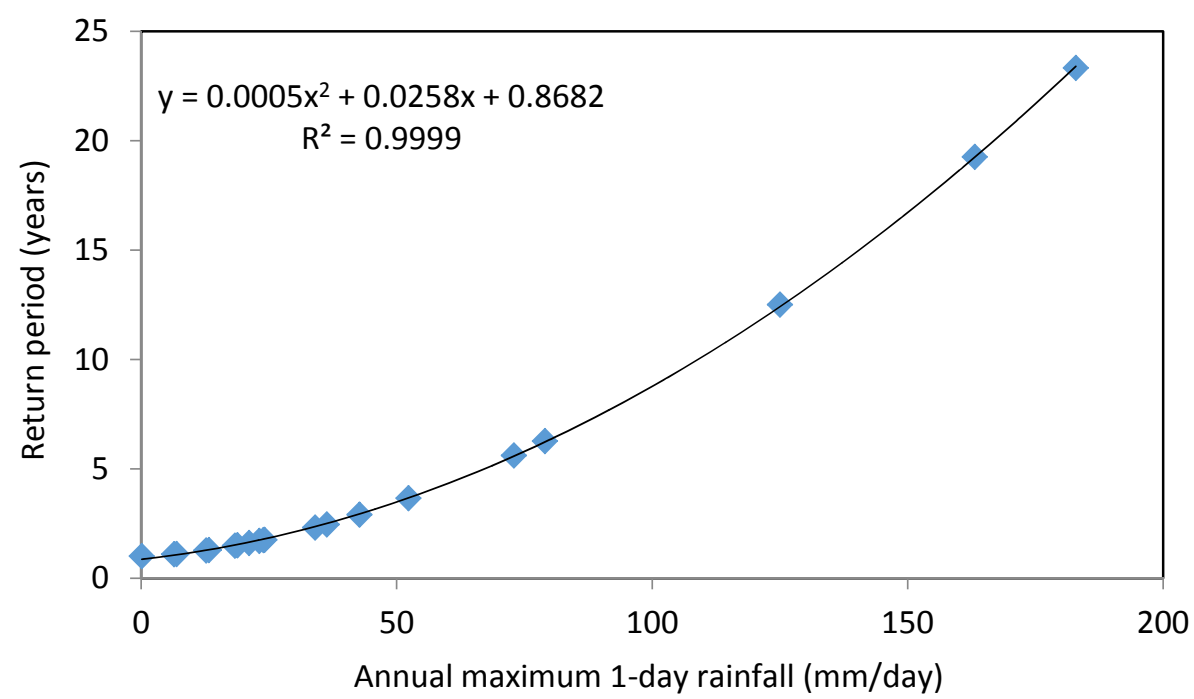

(a)

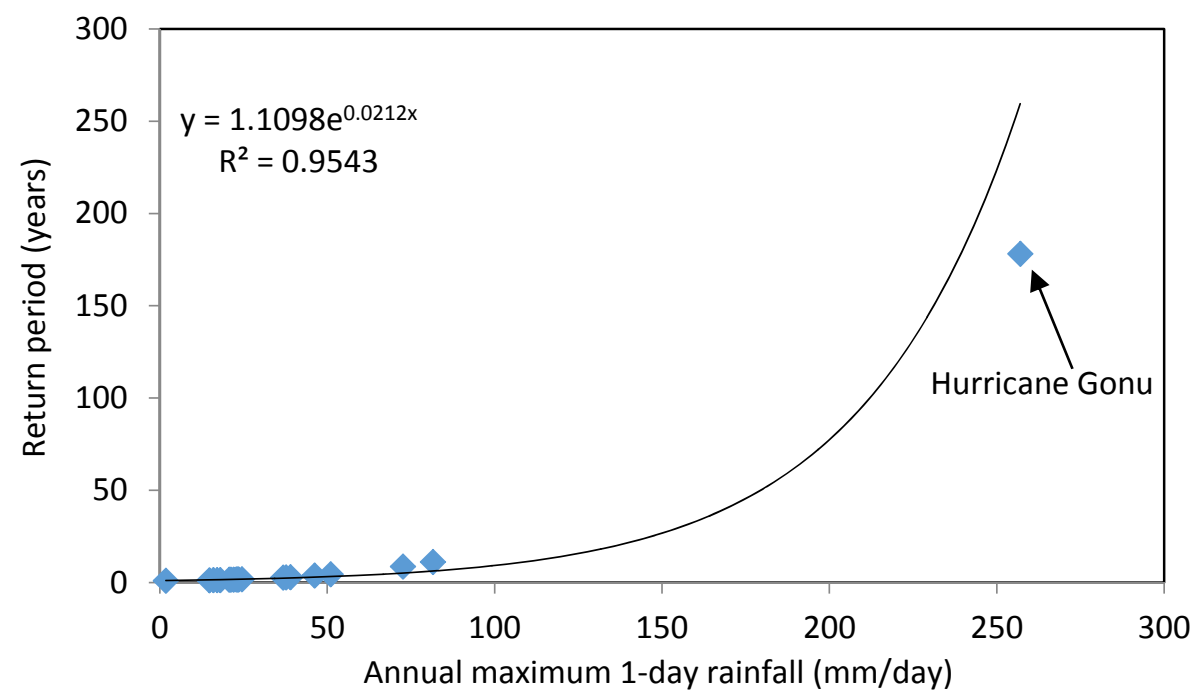

(b)

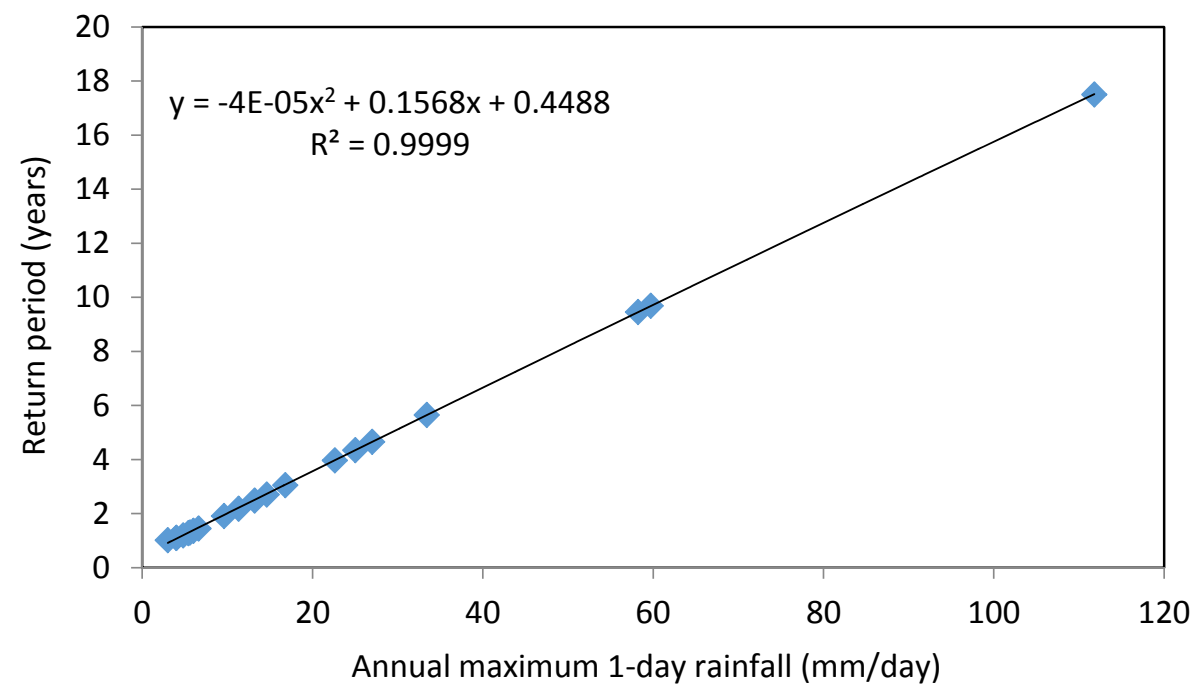

(c)

Figure 7. Return periods of annual maximum 1-day precipitation estimated by GEV distribution: (a) Sohar, (b) Muscat, and (c) Salalah. 


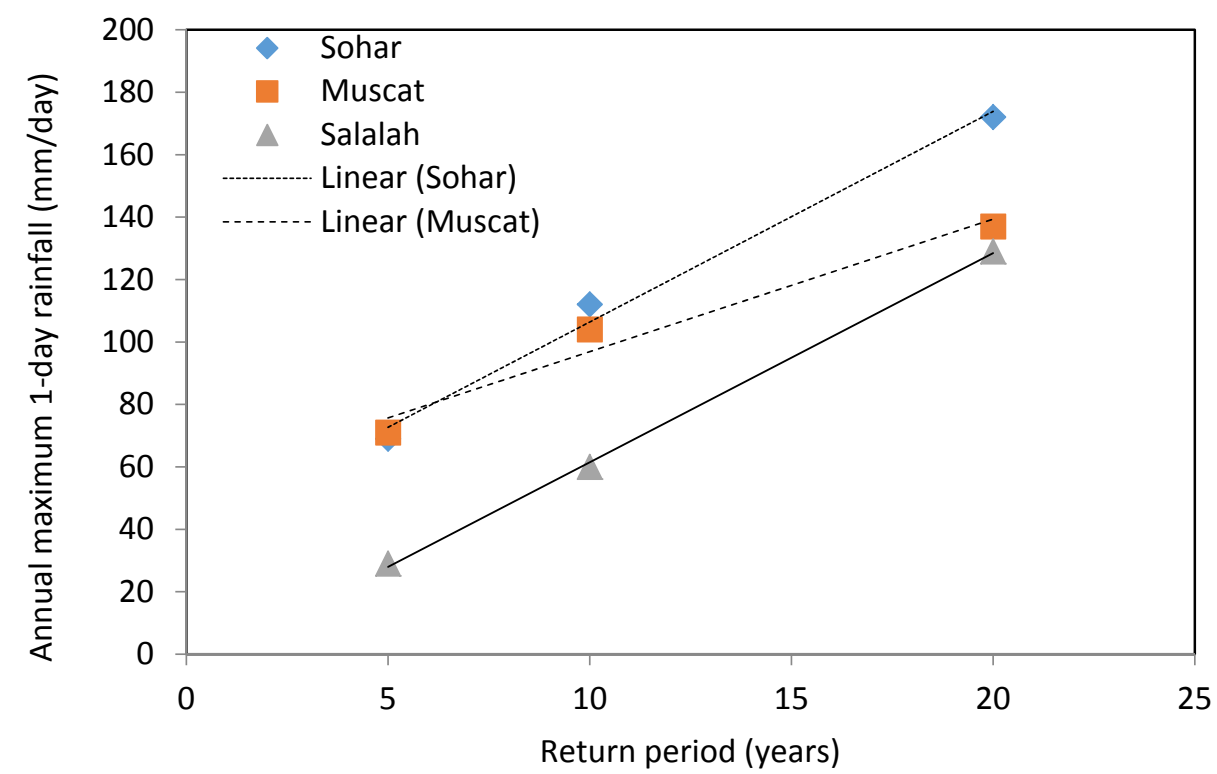

Figure 8. Annual maximum 1-day precipitation estimated for different return periods in three study areas.

periods in the three study areas. Results show that the annual Rx1-day rainfall estimated for the 5- and 10-year return periods in Sohar and Muscat are approximately the same, but are about two-fold greater than in Salalah. However, the rainfall for the 20-year return period in all three cities was estimated to be higher and reasonably close. This is because all of the study areas are affected by tropical cyclones, which bring occasional but heavy rainfall.

\section{Conclusion}

In this study, precipitation extremes in three major cities in Sultanate of Oman were examined using a set of climate indices. Moreover, a frequency analysis was conducted to understand the differences in annual maximum 1-day precipitation estimated for different return periods in the three study areas. In the end, the following conclusions were obtained.

The annual total precipitation in Sohar and Salalah decreased, especially in recent years, while that in Muscat slightly showed an increasing trend. This difference in Muscat is mainly because of the heavy precipitation caused by Hurricane Gonu in 2007. The average wet day precipitation intensity in Salalah is approximately $3.6 \mathrm{~mm} /$ day, which is significantly smaller than that in Sohar and Muscat (12 and $14 \mathrm{~mm} /$ day, respectively). This is mainly attributed to the frequent but low intensity rainfall events common in the Khareef season in Salalah. Despite the decrease in annual total precipitation estimated in Salalah, all indices analysed indicate enhanced extreme events toward 2010. Consequently, the contribution from extreme events to the annual total rainfall steadily increases in Salalah. The results in Muscat also lead to similar conclusion, which indicates that two-decades long wetting signal apparent in total precipitation can be attributed largely to the increases in extreme precipitation in recent decades. However, a comprehensible conclusion could not be made based on the selected indices for Sohar due to consistent drier years occurring from 1999 to 2005. An analysis using long-term data with focus on potential drought is therefore recommended for Sohar.

Consideration of time variant parameter in GEV distribution produced no significant changes in return levels in all three study areas. Frequency analysis conducted under the assumption of stationarity indicates that the annual maximum 1-day rainfall estimated for 5 and 10 year return periods in Sohar and Muscat are approximately the same but about two-fold greater than that in Salalah. However, the rainfalls for 20 year return period in all three cities were estimated to be higher and reasonably close. These results are expected to be useful for planning countermeasures for flash floods and persistent droughts in these study areas. 


\section{Acknowledgment}

This research was supported by the "Oman National Climate Change Strategy" project funded by the Ministry of Environment and Climatic Affairs (MECA) in Sultanate of Oman.

\section{References}

Alexander LV, Zhang X, Peterson TC, Caesar J, Gleason B, Tank AMGK, Haylock M, Collins D, Trewin B, Rahimzadeh F, Tagipour A, Kumar KR, Ravadekar J, Griffiths G, Vincent L, Stephenson DB, Burn J, Aguilar E, Brunet M, Taylor M, New M, Zhai P, Rusticucci M, Aguirre JLV (2006), Global observed changes in daily climate extremes of temperature and precipitation. Journal of Geophysical Research D05109, doi:10.1029/2005JD006290.

AlSarmi SH, Washington R (2013), Changes in climate extremes in the Arabian Peninsula: analysis of daily data. International Journal of Climatology 34: 1329-1345.

Beniston M, Stephenson DB, Christensen OB, Ferro CAT, Frei C, Goyette S, Halsnaes K, Holt T, Jylha K, Koffi B, Palutikof J, Scholl R, Semmler T, Woth K (2007), Future extreme events in European climate: an exploration of regional climate model projections. Climatic Change 81: 71-95.

Coopersmith EJ, Minsker BS, Sivapalan M (2014), Patterns of regional hydroclimatic shifts: An analysis of changing hydrologic regimes. Water Resources Research 50: 19601983.

Demaria EMC, Maurer EP, Thrasher B, Vicuna S, Meza FJ (2013), Climate change impacts on an alpine watershed in Chile: Do new model projections change the story? Journal of Hydrology 502: 128-138.

Fowler HJ, Ekstrom M, Kilsby CG, Jones PD (2005), New estimates of future changes in extreme rainfall across the UK using regional climate model integrations, 1 . Assessment of control climate. Journal of Hydrology 300: 212233.
Groisman PY, Knight RW, Easterling DR, Karl TR, Hegerl TC, Razuvaev VN (2005), Trends in intense precipitation in the climate record. Journal of Climate 18: 1326-1350.

Gunasekara NK, Kazama S, Yamazaki D, Oki T (2013), The effects of country-level population policy for enhancing adaptation to climate change. Hydrology and Earth System Sciences 17: 4429-4440.

Haren RV, Oldenborgh GJV, Lenderink G, Collins M, Hazeleger W (2013), SST and circulation trend biases cause an underestimation of European precipitation trends. Climate Dynamics 40: 1-20.

Jenkinson AF (1955), The frequency distribution of the annual maximum (or minimum) values of meteorological elements. Quarterly Journal of the Royal Meteorological Society 81: 158-171.

Kharin VV, Zwiers FW, Zhang X, Hegerl GC (2007), Changes in temperature and precipitation extremes in the IPCC ensemble of global coupled model simulations. Journal of Climate 20: 1419-1444.

Liu B, Chen C, Lian Y, Chen J, Chen X (2015), Long-term change of wet and dry climatic conditions in the southwest karst area of China. Global and Planetary Change 127: 1-11.

Stahli M, Badoux A, Ludwig A, Steiner K, Zappa M, Hegg C (2011), One century of hydrological monitoring in two small catchments with different forest coverage. Environmental Monitoring and Assessment 174: 91-106.

Tank AMGK, Zwiers FW, Zhang X (2009), Guidelines on analysis of extremes in a changing climate in support of informed decisions for adaptation (WCDMP-72, WMOTD/No.1500), 1-55.

Tezuka S, Takiguchi H, Kazama S, Sato A, Kawagoe S, Sarukkalige R (2014), Estimation of the effects of climate change on floodtriggered economic losses in Japan. International Journal of Disaster Risk Reduction 9: 58-67. 